\title{
El levantamiento popular del 2001 en Bizarra, de Rafael Spregelburd*
}

Fecha de recepción: 8 de abril de 2018

Fecha de aprobación: 29 de mayo de 2018

\section{Resumen}

En el año 2003, el dramaturgo Rafael Spregelburd pone en escena Bizarra, una comedia que versa sobre la crisis argentina del 2001. Se trata de la primera teatro-novela de la historia, es decir, una obra de teatro que consta de diez capítulos: hay que asistir diez veces al teatro para verla completa. Durante años, Spregelburd ha sido considerado, por una parte, de la crítica universitaria argentina y por dramaturgos de la generación de 1960, como un autor posmoderno. Este artículo se propone poner en cuestión esta clasificación fundamentado en la idea de que el autor tiene puntos de vista y prácticas en común con el teatro político.

Palabras clave: Spregelburd; corralito; Argentina 2001; teatro-novela; ideología; generación; revolución.

Citar: Di Pietro, L. F. (enero-junio de 2018). El levantamiento popular del 2001 en Bizarra, de Rafael Spregelburd. La Palabra,(32), 117-128. doi. org/10.19053/01218530.n32.2018.8169.

\section{Luciano Fabricio Di Pietro}

Profesor en UNAE- ECUADOR. Luciano Fabricio Di Pietro (1965 Buenos Aires-2018 Guayaquil), era un enamorado de la vida; se instaló en Europa y nunca abandonó sus lazos con la Argentina; dio sus pasos por Europa y América Latina: Italia, Francia y al final, el Ecuador. Fue militante político trotskista y de la solidaridad de los oprimidos; vivió en el teatro como dramaturgo, director y actor; era un amigo y compañero entero y leal. Nació y se formó en el Río de la Plata. Como muchos porteños, fue un verdadero saltimbanqui. Realizó sus estudios en el Conservatorio Nacional de Arte Dramático y su formación pedagógica en la Escuela Municipal de Arte Dramático. En Francia, se formó como guía intérprete en la Universidad de Nanterre. Obtuvo una Maestría de Investigación en la Universidad de la Sorbona Nueva y su doctorado en la Universidad de Perpignan. Fue profesor en la Universidad de las Antillas francesas. Se trasladó finalmente al Ecuador para ejercer en la UNAE de Cuenca, como profesor de lengua y literatura. En su actividad teatral, puso en marcha varias obras de su autoría en las décadas del 80 y 90 . Publicó también su novela, Los días anteriores en el 2006. florencialiff@gmail.com

*Artículo de reflexión. 


\section{la palabra \\ The 2001 Uprising of the Masses in Bizarra by Rafael Spregelburd}

\section{Abstract}

In the year 2003 the playwright and director Rafael Spregelburd stages Bizarra, a comedy about the Argentine crisis of 2001. This is the first theater-novel in history, that is to say, a play consisting of 10 chapters; in order to watch it complete, it is necessary to go ten times to the theater. For years, Spregelburd has been considered a postmodern author by several academic literary critics as well as by the dramaturgs of the 1960s generation. This article aims at questioning this classification based on the fact that the author has different points of view and practices in common with political theater.

Keywords: Spregelburd; Corralito; Argentina 2001; Theater-novel; Ideology; Generation; Revolution.

\section{Le soulèvement populaire de 2001 dans Bizarra,[ Bizarre] de Rafael Spregelburd}

\section{Résumé}

En 2003, le dramaturge Rafael Spregelburd met en scène Bizarra, une comédie sur la crise de l'Argentine de 2001. Il s'agit du premier roman-théatre de l'histoire, c'est-à-dire d'une pièce composée de dix chapitres: il faut aller au théâtre dix fois pour la voir en entier. Pendant des années, Spregelburd a été considéré par une partie de la critique universitaire argentine et des dramaturges de la génération de 1960 comme un auteur postmoderne. Cet article a pour but de remettre en question cette classification dans le mesure oú nous mettons en évidence les points de vue et les pratiques communes qu'il a avec le théâtre politique.

Mots-clés: Spregelburd; corralito; Argentine 2001; roman-théâtre; idéologie; génération; révolution. 


\section{Introducción}

En el año 2003, un evento teatral suscita un fenómeno que va más allá del teatro en una Argentina atravesada por crisis y revueltas: Bizarra. Es la primera teatro-novela de la historia, es decir, una pieza en diez capítulos que mezcla el formato de la telenovela (la serialidad) con el teatro, un arte en el que se reúnen actores y espectadores. La obra posee todos los clichés de las telenovelas (amores, desencuentros, personajes malvados y angelicales), pero todo puesto en un tono de comedia desenfrenada, cuasi «pornográfica» según el propio autor. Sin embargo, la gran particularidad de Bizarra es que trata sobre la revuelta argentina del 2001. La pieza tiene un alto contenido político desde varios puntos de vista: en primer lugar, por la forma de agruparse como elenco (en una cooperativa donde todos los integrantes son iguales); luego, por el fenómeno comunicacional inédito que se produce entre actores y espectadores; $y$, finalmente, por la reivindicación de la militancia que contiene el texto.

Para una parte de la crítica universitaria, Rafael Spregelburd era considerado un autor «postmoderno», producto de un conflicto entre autores de la nueva generación (entre los que se encuentra el mismo Spregelburd) $\mathrm{y}$ aquellos que comenzaron a escribir en los años 60. Asimis- mo, entre las críticas favorables a Bizarra, encontramos la de Jorge Dubatti, quien afirma que en la pieza «no se salva nada ni nadie, no hay personaje positivo ni moraleja bienpensante». Considero necesario debatir contra esos dos puntos de vista, a mi entender erróneos, e intentaré demostrar en este análisis, que el autor tiene puntos de vista y prácticas alejadas de la posmodernidad y que en Bizarra existen personajes positivos como el obrero revolucionario Hugo Capriota y la artista Trisha Hinge.

Bizarra es una obra que tiene como tema principal la revuelta de masas del 2001, que hizo caer al neoliberalismo en Argentina, y fue puesta en escena en 2003, cuando los fuegos del levantamiento aún no se habían apagado. La relación que se logró con el público fue irrepetible, ya que no hay texto sin contexto, y como decía Jerzy Grotowsky (1968) "no hay teatro sin público" (p. 13). El evento Bizarra se produce también en la medida en que hay espectadores imbuidos de ese clima de crisis terminal de 2001.

La primera parte consiste en un análisis de la trayectoria y el pensamiento de Spregelburd y la polémica con los autores de los años 60. Posteriormente, focalizaré en el significado del evento Bizarra y por qué superó los marcos del teatro tradicional. La última parte discute la ridiculización del militante como «un signo reaccionario», tratando de demostrar con base al texto de la obra que, lejos de una visión posmoderna, se está haciendo una reivindicación del militante revolucionario.

Trayectoria y el pensamiento de Spregelburd y la polémica con los autores de los años 60

Rafael Spregelburd, nacido en 1970, es uno de los más importantes (y uno de los más prolíficos) dramaturgos en la actualidad, también es actor y director. Como muchos de los dramaturgos argentinos actuales, comenzó como actor. A sus 45 años, ya ha estrenado 30 piezas de su autoría. Las primeras, Cucha de almas y Destino de dos cosas o tres, tienen influencias del absurdo de Ionesco o Adamov. Sucesivamente, se va a encontrar dentro de un género aproximado al absurdo social, donde la ironía y lo insólito priman sobre el realismo. Es uno de los grandes renovadores de la comedia en Argentina, no tiene pruritos en pasar del humor más refinado al más grosero en una misma obra, a veces en una misma escena sin que esto le quite calidad a la pieza.

Uno de los puntos claves de su vida es la creación del grupo Caraja-jí. En 1996, el teatro San Martín (teatro oficial de la ciudad de Buenos Aires) decide lanzar la Comedia Juvenil y encargan al famoso dramaturgo 
Roberto Cossa la convocatoria de jóvenes dramaturgos. Entre ellos, se encuentran Javier Daulte, Alejandro Tantanián, Ignacio Apolo, Jorge Leyes, Carmen Arrieta y Rafael Spregelburd, por mencionar algunos. Después de dos meses de reuniones, Cossa, junto con Juan Carlos Gené (actor y dramaturgo, en aquel momento director del Teatro San Martín), les piden a los autores el material tal como estaba en ese momento. Los autores, que tenían sus piezas escritas por la mitad, le dijeron a Cossa que mostrar las piezas en el estado actual "es como estar en camisa, corbata y calzonci1los" (Dosio, 2008, p. 27). Pero los directores insistieron, y luego de leer los escritos decidieron concluir la experiencia, ya que, a su parecer, las obras carecían de "humor, pasión y ternura" (p. 28). Los jóvenes dramaturgos no se desmoralizaron luego de ser expulsados del taller del teatro oficial. Finalmente, decidieron continuar solos y evaluar en grupo las piezas de cada uno. Una vez finalizadas, le pusieron al grupo el nombre Caraja-jí, que son las iniciales de los autores.

La dirección del Centro Cultural Ricardo Rojas (que es una dependencia universitaria y, al mismo tiempo, un polo de la cultura alternativa de Buenos Aires) le propuso a los autores publicar el libro con las obras y les ofreció sala para estrenarlas. Para el Teatro San Martín, se trató de un error trágico: por primera vez, después de decenios, se produce un enfrentamiento entre dramaturgos de distintas generaciones, justamente, cuando nace una nueva camada que va a renovar la dramaturgia en Argentina. Una buena parte de los integrantes del Caraja-jí se transforma rápidamente en dramaturgos con fama internacional, y Rafael Spregelburd es uno de los que adquiere mayor proyección fuera de la Argentina.

Pese a todo, una parte de la crítica teatral considera a estos autores como posmodernos, desinteresados de lo social. Algunos autores que comenzaron su carrera en los años 60 retomaban esa idea. Eduardo Pavlovsky, un prestigioso autor de aquella generación, que no había tenido ningún conflicto personal con los integrantes del Caraja-jí, opinaba de manera similar sobre estos autores, y mencionaba especialmente a Spregelburd:

Para mí el posmodernismo es el teatro que hacen algunos, que no tiene nada que ver con el anclaje político, y que se define más bien como a-político. Que no les interesa, y son algunos autores de bastante éxito. Como Daulte,
Spregeburd, Federico León. Pero que no tienen nada que ver con la política, ellos dicen que la política la leen en el diario Clarín (Di Pietro, 2009, p. 110) ${ }^{1}$.

Luego, veremos que se trata de un malentendido, en especial, en lo que se refiere a Rafael Spregelburd.

Nuestro autor cree que vivimos la «agonía de la modernidad», no hay un Dios en el centro, ya que desde su punto de vista ni siquiera hay centro, y sostiene que este orden de la modernidad se encuentra en un estado terminal, ya que «lo que cayó en el este no era comunismo y lo que hay en el oeste no es libertad» (Spregelburd, 2008b). Otra de las características del teatro de este autor, es que en la mayoría de sus obras no hay protagonistas, en general, son obras corales. Dentro de esta lógica, una de las particularidades (muy extendida en el teatro argentino actual) es que el dinero que se gana se divide en partes iguales entre los integrantes del elenco. Spregelburd está en contra de una pirámide jerárquica encabezada por el autor, seguida por el director y terminada por los actores y técnicos, considera que esta es una postura política, ya que, si hay jerarquías en los elencos, aún el mensaje más progresista será falso. Este es también un fenómeno bastante

1 Entrevista realizada por el autor en el marco de la investigación de la tesis de Maestría. Grabación de entrevista telefónica, París-Buenos Aires, marzo 2009. 
común en la nueva generación de «teatristas» en Argentina, y es una de las razones de que se lo llame «teatro de actores».

Uno de los prejuicios que se tiene con algunas obras del autor, es que son «largas»: desde su punto de vista, el problema no es la duración de algunas de sus puestas, sino la estructura social.

La duración de una obra es lo que la cultura que la ve nacer pueda permitirse como tiempo robado (tiempo ocioso) al funcionamiento del capital que se mueve en sus estructuras más profundas, [...] la capacidad de ocio, de sustracción de utilidad de las operaciones de producción de mercancías, que cada sociedad [se] permite (Spregelburd, 2008b).

Para Spregelburd, así como para una buena parte de los autores de su generación, el teatro es algo lúdico, un juego. Ellos consideran que el teatro no puede cambiar al mundo, ya que este solo puede ser transformado por grandes movimientos sociales y no por una simple pieza de teatro. Spregelburd considera al teatro, como "una farsa", algo "falso", una falsedad aceptada por los espectadores una determinada cantidad de minutos; finalmente, que se tra- ta nada más y nada menos que de ficción. Opina que el público es consciente de que se trata de ficción y que eso es lo que atrae, «queremos ir a que nos cuenten historias, porque sabemos que son mentira $»^{2}$ (Di Pietro, 2014, p. 310). Y como se trata de un juego, y no de la realidad, se pueden imponer nuevas reglas, como variar la temporalidad, dirigirse al público, no buscar un final preciso, etc. También considera que la tragedia «donde se encuentran enfrentadas las fuerzas del bien y del mal hay una mirada cristiano-hollywoodense» (Di Pietro, 2014, p. 311) no es un género para el hombre actual, mientras que en la comedia hay mayores posibilidades de vías de fuga y de hechos inesperados.

Esta actitud ha llevado a que una parte de los autores y críticos argentinos consideren a Spregelburd, como a muchos otros autores de su generación (desde manera equivocada a mi parecer), un artista pasatista y posmoderno. En Historia del teatro argentino en Buenos Aires, se puede leer, respecto de los autores de esta generación, que: "Estas obras presentan un pesimismo intenso: para Pelletieri muestran la desintegración textual y social, la incomunicación familiar, la violencia gratuita, la ausencia de amor en la convivencia posmoderna" (Rodríguez, 2008, p. 464). El equívoco proviene de pensar que solo el realismo puede expresar ideas políticas de izquierda o progresistas, pero Spregelburd lo desmiente rotundamente:

Peu importe si j'utilise un canevas de sitcom télévisé avec une construction de scènes courtes, peu importe, pourvu que j'arrive à créer une subjectivité, des opinions subjectives qui ne soient pas dominés par une intention, un objectif de marché. (Martin \& Perrier, 2010, p. 84) $)^{3}$.

Enfocar el arte desde un punto de vista lúdico, no implica automáticamente una desatención de los problemas sociopolíticos, sino que permite jugar con ellos y desenmascarar la realidad a través de caricaturas grotescas. La paradoja más curiosa es que, mientras que en Argentina Rafael Spregelburd es definido como teatro de intertexto posmoderno (Rodríguez, 2009, p. 464), en Europa es estudiado como teatro político. El autor es uno de los pocos artistas argentinos que dice analizar la realidad desde el punto de vista de la lucha de clases, que, afirma "no es el único análisis posible, pero sí el único científico" (Spregelburd, 2008, p. 528). Y más aún, «[el teatro es] un fait ajouté à la réalité et non pas une opinion sur la réalité comme par

2 Entrevista realizada por el autor en diciembre del 2010 en Buenos Aires en el marco de la tesis doctoral citada en este artículo.

3 "Poco importa si yo uso un borrador de serie televisiva con una construcción de escenas cortas, poco importa, siempre que llegue a crear una subjetividad, opiniones subjetivas que no estén dominadas por una intención, un objetivo de mercado. (Traducción mía)". 
exemple : la classe ouvrière doit prendre le pouvoir. Ce que, par ailleurs, je pense effectivement $»^{4}$ (Martin \& Perrier, 2010, p. 85).

Y si es imposible no encontrar intertextos políticos en la totalidad de las piezas de Rafael Spregelburd, es más difícil negar la existencia de obras con referencias directas, como por ejemplo Acassuso, donde se muestra la realidad monstruosa de la escuela argentina de una manera hilarante; en Bloqueo, una pieza sobre la revolución cubana; o Un momento argentino, donde el centro de la acción es una hija de desaparecidos que amenaza con una bomba a su secuestrador militar. Pero, si hay una pieza en la cual Spregelburd entra de lleno en la política «coyuntural», es Bizarra.

\section{Repercusión del evento Biza-} rra y superación de los marcos del teatro tradicional

Bizarra es uno de los espectáculos más especiales que se vieron en Argentina en los últimos años, y ya es considerada una obra de culto. En primer lugar, se trata de una teatro-novela. Para salvar los malos entendidos, cuando hablamos de teatro-novela nos estamos refiriendo al género tan desarrollado en América Latina de las telenovelas. En efecto, Bizarra es una obra hecha en diez capítulos de más de dos horas cada uno, que hay que seguir para no perderse la trama, y los espectadores tienen que ir diez veces al teatro para ver la obra completa: es, seguramente, una de las obras de teatro más largas del mundo. Pero, la especificidad de esta teatro-novela consiste en que el tema principal de la obra es la revuelta social argentina del 2001.

Bizarra fue hecha en Argentina en el año 2003. En ese momento, la gran crisis política y económica argentina dominaba la realidad cotidiana. La caída del gobierno neoliberal de De La Rúa se había producido por un levantamiento de masas. Este hecho demostraba (al menos a nivel continental) dos cosas: que el discurso que decía que el liberalismo era la solución a los problemas económicos era una falacia completa; y segundo, que se lo podía derrotar, que no eran invencibles. Sin embargo, inmediatamente después de las jornadas revolucionarias del 2001 no siguió un gobierno de signo opuesto al neoliberalismo, sino un gobierno derechista débil en medio de un período de caos y luchas sociales. Se multiplicaron las asambleas populares, las fábricas ocupadas autogestionadas y se legitimaron como métodos de lucha el piquete y el corte de ruta. La moneda escaseaba, y el gobierno emitió una serie de bonos de dudoso valor que debían reem- plazar al peso; la confianza en la autoridad estaba en sus mínimos históricos.

En ese momento particular, existía una dualidad en la población argentina, de un lado la miseria era inédita (en particular era una novedad para la clase media) y esto provocaba una gran depresión; por otro lado, existía el orgullo de haber hecho caer un gobierno manifestándose en las calles, lo cual agrandaba el ego. Era un país nuevo. A esto se le tenía que sumar que la revuelta del 2001 ocurrió tan solo tres meses después del atentado contra las Torres Gemelas, lo que provocaba en buena parte de la población (y la intelectualidad) argentina la sensación de estar viviendo el fin del mundo. Todo este contexto, favorecía nuevas reflexiones, como dice el autor "La sensación es que solo en las crisis más profundas se vuelve a discutir sobre lo más fundamental, sobre lo verdadero, sobre lo básico" (Di Pietro, 2014, p. 318).

Spregelburd, en el 2002, reúne a más de treinta actores sin trabajo y decide hacer algo para salir de la tristeza de la crisis haciendo lo que saben hacer: teatro. Es preciso aclarar que, el teatro argentino actual es un movimiento inmenso: en la ciudad de Buenos Aires hay 400 salas de teatro que convocan al-

4 «Un hecho agregado a la realidad como, por ejemplo: la clase obrera debe tomar el poder. Que, por otro lado, es lo que pienso efectivamente.» 
rededor de 800 espectáculos por semana. Muchos de ellos son gratuitos, los actores no ganan nada o casi nada por hacer los espectáculos. Como dice Spregelburd:

El teatro en Argentina es una forma de vida y no una profesión, para bien y para mal, ya nos gustaría a nosotros cobrar del Estado, pero tenemos un Estado muy empobrecido. Igualmente tenemos una gran cantidad de personas que quieren hacer teatro y lo hacen igual. (Di Pietro, 2014, p. 320 ).

Para integrar a más de 30 actores en un mismo emprendimiento, el autor decide crear la primera teatro-novela de la historia. Los motivos para la elección de un género que nunca había tenido relación directa con el teatro, y menos con el teatro de arte, son los siguientes:

La telenovela latinoamericana tiene características estilísticas muy extrañas. Como género es una porquería, pero tiene cosas curiosas e interesantes. Es un híbrido que está a mitad de camino entre el cuento de hadas y el estilo gótico arquitectónico, muchos puntos de apoyo. En las telenovelas hay cuarenta líneas narrativas al mismo tiempo, miles de personajes que sostienen la cúpula central, que es el encuentro amoroso entre la heroína y su amado. (Di Pietro, 2014, p. 317).
Spregelburd mantiene el formato de la telenovela, pero viola dos reglas:

Una de las reglas de la telenovela dice que no se puede hablar de política, porque ya que es un producto masivo nunca puede identificarse con un partido o con una idea. La otra regla dice que en la telenovela hay mucho deseo erótico, pero que nunca se consuma. (Di Pietro, 2014, p. 317).

Entonces, al contrario de las telenovelas, la política es omnipresente en el texto y la sexualidad siempre se consuma. Pero, respetando las otras reglas de la telenovela, la historia contiene todos los otros elementos del género: las mentiras que no se pueden revelar, un paralítico que vuelve a caminar, la hija que no sabe quién es en realidad su madre, hermanas que no saben que lo son y se tratan regularmente, números musicales, amores imposibles, gente que recupera la memoria o la pierde, embarazos verdaderos y falsos, niños que se pierden y vuelven, y por supuesto, una heroína inocente que está enamorada de un hombre que no la acepta hasta el final. Esto último es importante, ya que en las telenovelas (al menos en la gran mayoría) una mujer enamorada es la protagonista y no un hombre. Pero como Bizarra es una obra de Spregelburd, y no una telenovela clásica, este elemento es importante, pero no el eje, ya que sigue siendo una obra coral, con cien personajes hechos por más de treinta actores, y decenas de protagonistas.

Los dos personajes que conforman el eje primario de la trama son Candela y Velita, dos hermanas gemelas separadas al nacer que no conocen su verdadera identidad. Candela es rica e ideóloga de su clase: en la pieza aparece como la creadora de las medidas económicas que llevaron a la ruina a Argentina (entre ellas, el famoso corralito). Por el contrario, Velita es una obrera pobre, analfabeta e inocente: cada capítulo sufre una vejación diferente. Tenemos también a las dos «madrastras»: Felicia Auster, la falsa madre de Candela, que es una millonaria estafadora; y Wilma Bebuy, pobre y cruel, que se hace pasar por madre de Velita. Entre los casi cien personajes, se encuentran empresarios abusadores, caudillos políticos, policías corruptos, militares ineptos, pobres desesperados, enamorados varios, e inclusive Dios y el Diablo. Pero hay dos personajes que son significativos en particular para comprender mejor la pieza: Paola Moto, de nombre artístico Trisha Hinge, que es una artista de vanguardia que trabaja para Felicia Auster, y dibuja ositos y tortugas que Felicia Auster vende en cientos de miles de dólares; y Hugo Capriota, que es un sindicalista trotskista que trabaja en el frigorífico con Velita, él 
dice cosas que son justas, pero nadie lo entiende.

Todos los personajes tendrán un rol importante hasta el último capítulo. En la vorágine de los acontecimientos, en medio de robos, amenazas, mentiras, violaciones, represión, orgías, amor y lucha de clases, se entremezclarán discusiones sobre filosofía, matemática, economía, el rol de la justicia, el arte como mercancía y hasta un debate sobre la nueva dramaturgia argentina. Spregelburd definió a su obra como «la lucha de clases explicada a los niños, con pornografía y una pizca de pop»» (Ordoñez, 2009, p. 28).

Bizarra se transformó en un fenómeno que iba más allá del teatro. La obra se presentó en el Centro Cultural Ricardo Rojas, en una sala de 200 espectadores, 5 veces por semana cada capítulo, a sala llena, o sea 50 funciones con 10.000 espectadores en total. Muchos espectadores no conseguían entrada después de largas filas de espera. La entrada era popular, costaba 3 pesos (un dólar en aquel momento), por lo tanto, no quedaba mucho dinero para los actores, muy numerosos.

El fenómeno que se dió en el público fue algo inédito, tener que ir una vez por semana a ver el espectáculo generaba una relación entre ellos. Semana tras semana los espectadores comenzaban a conocerse, se hablaban, se formaban relaciones de amistad. Pero, uno de los puntos decisivos que ayudaba a la comunicación entre los espectadores, fue el álbum de figuritas de Bizarra. El público compraba las figuritas, ya que habían prometido que quienes llenaran el álbum, podrían participar en un concurso para actuar en el último capítulo de la obra. Esto llevaba a que la gente se comunicara para intercambiar las figuritas que tenían repetidas. Obviamente, terminaban hablando de la obra, de ellos, de la Argentina. Capítulo tras capítulo, el público tenía más la sensación de asistir a una fiesta con amigos.

¿Qué es el teatro? Una de las concepciones actuales del teatro, dice que este es un convivio, un lugar donde se juntan personas, ya que es un fenómeno que solo puede ser posible cuando hay al menos un actor y un espectador: es una reunión de personas, una celebración. Es un fenómeno efímero e irrepetible, que quedará solamente en el interior de las personas que asistieron al acto. Hablando de Bizarra, el dramaturgo argentino Javier Daulte explica:

Es que el acontecimiento teatral no se termina en su categoría artística. Yo creo que el teatro recupera su mayor especificidad cuando se transforma en celebración. Es decir, el teatro es un acto de celebración. Cuando esa celebración se produce (por- que no siempre se produce) es cuando el teatro cobra sentido pleno y se hace presente como fiesta y ahí nada importa: no importa que sean buenos actores, no importa que sea bueno el texto (Spregelburd, 2008a, p. 518).

Finalmente, con esta celebración Bizarra deviene un fenómeno político, una "polis" que celebra, en medio de los remezones de la crisis del 2001, una fiesta entre las ruinas.

La Reivindicación de la militancia revolucionaria a través de dos personajes positivos: Trisha Hige y Hugo Capriota

Jorge Dubatti, uno de los críticos teatrales más importantes de la Argentina, dice que:

este texto que afianza una de las modalidades más interesantes del teatro de Spregelburd: su línea explícitamente política, ejercida a través de una virulenta crítica social. No se salva nada ni nadie, no hay personaje positivo ni moraleja bienpensante. Como más tarde en Acassuso y Bloqueo, Bizarra arrasa, pulveriza todos los discursos sociales para construir la metáfora de un país impresentable, berreta, insostenible, con formato de telenovela, que se parece mucho a nuestra Argentina (Damore, 2009).

Si bien Dubatti señala con claridad el carácter político y de 
crítica social de la obra, la afirmación: que «no se salva nada ni nadie, no hay personaje positivo...» se desmorona producto de este análisis. Hay dos personajes que aparecen como los más ridículos, y terminan siendo asumidos como personajes positivos. Ellos son el obrero trotskista Huguito Capriota y la artista Trisha Hinge. La ridiculización del militante ha sido entendida por algunos autores como «un signo reaccionario» (Duran, 2003), pero un análisis en profundidad demuestra que en realidad, se trata de lo contrario.

Paola Moto, alias Trisha Hinge, es una pintora que es atraída por la rica Felicia Auster, quien la convence de pintar para ella. En su personaje se condensa la polémica sobre el arte como mercancía. Las obras de Trisha nunca se ven, pero todo hace suponer que son ridículas. Según el texto, ella hace «ositos y tortugas que Felicia las vende en miles de dólares». Se puede pensar que el autor eligió el nombre Trisha en una especie de homenaje/burla a Trisha Brown, bailarina, coreógrafa y artista plástica norteamericana de vanguardia. Trisha Hinge es ridícula (la llaman «tele tubbie» y su voz era gangosa) y parece no darse cuenta de las cosas, pero sus reflexiones suelen ser filosas. Y en el capítulo 6 comienza su noviazgo con Capriota. El joven obrero trotskista Capriota es víctima de las burlas de todos porque consideran que lo que dice es ridículo, $\mathrm{y}$, sobre todo, incomprensible. Por ejemplo, en el capítulo 9, una periodista de la $\mathrm{CNN}$ en español, después de escuchar su arenga, no sigue su entrevista con él porque dice que "nuestro entrevistado no habla castellano". El hecho de que Capriota sea un incomprendido es remarcado por el profesor Topuzian (2004):

El hecho de que esa resistencia del público, manifestada en la obra en los múltiples interlocutores del sindicalista Capriota, pueda fácilmente confundirse con simple sordera, estupidez o autoengaño no hace más que agregar otro interesante contrapunto a la maraña de significantes de Bizarra. (p. 12).

A modo de ejemplo, en el capítulo 4, transcurre una de las tantas escenas que muestran la incomprensión del discurso de Hugito Capriota de parte de sus pares. Capriota quiere advertir a los obreros que una máquina en mal estado puede llegar a amputar a los obreros, y lo hace a su manera: «Esta máquina es una mogólica analogía del plan de explotación sistemático que mantiene en pie al capitalismo: la sangre obrera da de comer a sus hijos en sus colegios bilingües» (Spregelburd, 2008a, p. 146).

El capataz es el único que lo entiende y contraargumenta:
Ya lo ve, nadie entiende lo que usted dice, Capriota. Lo que estos obreros entendemos es el trabajo. Y el trabajo dignifica. Yo estaba perdido, hasta que encontré este trabajo y me hice digno de él. Yo le pegaba a mi mujer porque no me sentía un hombre completo hasta que empecé a trabajar acá. Pero nada es eterno, y el trabajo se defiende con trabajo. Si de esta máquina no salen prolijas tiras de asado, a lo mejor vuelvo a pegarle sin querer a mi mujer. (Spregelburd, 2008a, p. 146).

El argumento conmueve a la heroína Velita, también obrera del frigorífico. Huguito intenta impedir que ella manipule la máquina defectuosa, pero ella le responde: "Dejame, Huguito, vos sos bueno, pero es cierto: pero a vos no se te entiende, y a él sí. Habla con verdad, sin tanto rulo" (Spregelburd, 2008a, p. 147). Y Capriota, sin sutilezas le contesta: "Son todos unas bestias. ¡Bufones del capital! ¡Se regodean en la ignorancia! Porque es más fácil creer en un sueño de mentiras que tomar coraje y cambiar el curso de la historia" (Spregelburd, 2008a, p. 147). El final de la escena es previsible, Velita se pone a trabajar y la máquina le corta un dedo.

En el capítulo 10, el final, se produce el asesinato de Capriota. Los obreros del frigorífico van a ocupar la planta. Allí se encuentra Velita, quien ya no 
es más obrera, pero se va a casar en la fábrica porque que su dueño los ha invitado a hacerlo allí, y quiere impedir la ocupación para que no interrumpan su largamente soñado matrimonio. Pero, entre los obreros, se encuentran policías infiltrados que terminan matando a tiros a Capriota.

Es muy llamativo que, en la puesta en escena porteña, los estertores de la muerte del sindicalista de ficción, son los mismos que había hecho en la realidad el activista de los desocupados Maximiliano Kosteki, asesinado por la policía en la estación de Avellaneda en el 2002. La muerte de Kosteki (junto con otro activista, Darío Santillán) significaron el fin de la denominada «transición» de Eduardo Duhalde en la presidencia con el inmediato llamado a elecciones. La imagen de la muerte de Kosteki estaba muy presente en el imaginario de los argentinos a pocos meses de los hechos. Y obviamente, seguían presentes en los espectadores de Bizarra. Mientras que, en el resto de las escenas del capítulo, el público festejaba cada escena con aplausos cuasi de estadio de fútbol, al terminar esta escena se produce un fuerte silencio, $y$ luego un aplauso contenido.

Entre la «maraña de significantes», como la llama Topuzián, Capriota termina como mártir, y así es entendido por el público. $\mathrm{Su}$ personaje, antes ridículo, se transforma en positivo con la operación de cambiar el punto de vista. Con su muerte, se produce un replanteo por parte del espectador de la actuación del sindicalista durante toda la teatro-novela. Además, se produce un momento único, que podríamos llamar «pecado de lesa telenovela»: logra que el público se ponga (momentáneamente) en contra de la heroína Velita. En efecto, ella dice «igual me tengo que casar» poniéndose en un rol patético. La socia de Capriota, la artista Trisha Hinge termina la escena diciendo «Esto no va a parar», agregando una carga de dramatismo. Las muertes de diciembre del 2001, más aquellas de Kosteki y Santillan, eran muy recientes y la escena hacía una referencia abierta a esos hechos, en los que la mayoría de los argentinos había tomado posición, considerándolos víctimas, por lo tanto, personajes positivos.

La otra curiosidad del personaje llamado Capriota es que sea trotskista. En efecto, no hay muchos personajes trotskistas en la dramaturgia argentina, y en lo que respecta a los dramaturgos, el único dramaturgo conocido que en el pasado fuera un militante de esas ideas es Eduardo Pavlovsky. Spregelburd se ha reivindicado en reiteradas oportunidades como un hombre de izquierdas, aunque rechace el arte llamado «didáctico». Esto último le ha valido ser considerado como posmoderno por un sector de la crítica. Sin embargo, en el 2003, al mismo tiempo que Bizarra, estrena otra obra de su autoría, La Estupidez; en el prefacio de esta obra, hace una sugerente reivindicación de las reflexiones del trotskismo o de ciertos trotskistas.

Allá por el 2000, minutos antes de que se acabara el milenio, llegué de manera más o menos azarosa a encontrarme con los miembros de un grupo de estudios trotskystas. Ellos editaban en ese momento una publicación en la que recogían sus debates y análisis políticos. Les dije que me interesaba mucho recibir la publicación y -para mi sorpresa- ellos me preguntaron por qué. No estaba acostumbrado a esa pregunta. A diferencia de otras agrupaciones de izquierda, siempre ávidas de darles difusión a sus periódicos y de sumar adeptos de entre las filas de cualquier facción, a la gente de Piedra le interesaba más -creo yo, en una pausa de extrema y lúcida tristeza- la idea de preservar un conocimiento. Lejos de la propaganda y más cerca de la reflexión, supongo que economizaban -y con razón- sus periódicos caseros. Estoy seguro que allí está el germen de Finnegan. $\mathrm{Y}$ el de esta obra. Son tiempos estúpidos, ¿qué ocurre con la razón cuando no hay nadie que esté en condiciones de oírla bien? ¿Se deforma, se adapta? ¿Solo para que ALGUIEN sea capaz de percibirla? ¿O es preferible conservarla pura, en la espe- 
ra optimista de épocas mejores? De más está decir que por motivos estrictamente teatrales (pérfidos motivos lúdicos) nuestro Finnegan está lejos de ser el héroe que Piedra, que nuestra época reclaman. (Spregelburd, 2004, p. 9).

La coincidencia es muy grande: un grupo de trotskistas inspiran la idea de una pieza ( $L a$ estupidez) y en la otra pieza que se actúa en contemporáneo hay un personaje de la misma ideología que no es escuchado y muere como mártir. Entonces, ¿es Capriota alguien que apela a la razón «cuando nadie esté en condiciones de oírla bien»? ¿Es Capriota el héroe que Piedra, que nuestra época reclama? Es una de las interpretaciones posibles.

Respecto de su compañera Trisha, desde que se conoce con Huguito, le propone formas estéticas para darle visibilidad a las protestas organizadas por el sindicalista y toma como ejemplo de imagen al servicio de una lucha a los zapatistas, que con sus pasamontañas crearon un imaginario. Pero es finalmente en el capítulo 9, en el cual se escenifican saqueos, cuando Trisha Hinge expresa un artista que encuentra una estética (y una ética) positiva en las luchas sociales. A continuación, una conversación con una periodista de CNN en español:

Molly: ¿Cuál es tu participación en estos disturbios?
Trisha: Una participación expectante. Soy espectadora atónita. No puedo dejar de ver esta rabia en forma de colores, colores que pasan a toda velocidad. Fideos que van, sachets de leche que explotan en puro movimiento sin ideología... Alguien debería ordenar esto, reseñarlo, y dejarlo congelado, no para aprendizaje, sino para goce estético.

Molly: ¿Gozas viendo el derrumbe de tu país, cariño?

Trisha: Del derrumbe se hacen escombros. De los escombros habrá manos que sepan construir algo en serio. Esto se acaba, señorita $\mathrm{CNN}$ (Spregelburd, 2008a, p. 424).

Durante el capítulo 10, Trisha muestra su continuidad con las ideas de Capriota, quien ya había muerto. Ella hace un soliloquio con una imagen de fondo de la Plaza de Mayo en el que dice "A poner sus relojes en hora señores, hoy es 19 de diciembre del 2001, hoy hay motivos para salir a la calle. Y habrá que aprender a verlas de otra forma. Allí, en la calle, nadie conoce a nadie. Pero es la guerra. El enemigo es el de siempre, pero nadie lo sabe. Todavía." (Spregelburd, 2008a, p. 466). Y, finalizando, afirma «Estarías orgulloso de mí, Huguito» e inmediatamente el público saluda con un aplauso atronador. ¿Se puede inferir de esto que la artista continúa la obra del militante trotskista asesinado? Es una de las interpretaciones más evidentes.
La artista "ridícula" pasa a ser comprendida por el público. El capítulo 10, el final, provoca un giro de 180 grados en el punto de vista de los personajes Capriota y Hinge: lejos de pensar que «No se salva nada ni nadie, no hay personaje positivo ni moraleja bienpensante», estos expresan una salida.

\section{Conclusión}

Bizarra fue de por sí un evento político. Miles de personas se juntaron y gracias al teatro hablaron y reflexionaron sobre la cercana crisis del 2001 y su presente. El precio cuasi simbólico de las entradas no ponía un límite de clase al público. La idea de que el autor fuese un posmoderno desinteresado de la política que ya era difícil de sostener antes, luego del evento Bizarra se hace impensable.

Que la pieza sea una comedia desenfrenada no significa que "no se salva nadie": bien leída, no impide ver a quien lo quiera que hay dos personajes, un trotskista y una artista, que eran los únicos que podían realmente interpretar lo que sucedía y proponer una salida positiva. La alianza entre la artista y el trotskista, tal vez, expresa la necesaria unión entre lo racional y lo sensible para interpretar y resolver los problemas sociales.

Finalmente, Bizarra niega rotundamente el prejuicio que dice que para tratar la realidad 
social haya que utilizar solo un formato realista. Mientras que para la mayoría de los autores argentinos su tema de predilección es la dignidad frente a la derrota, en Bizarra hay otra salida posible: la de Capriota y Trisha Hinge, la salida revolucionaria. Como afirma el mismo autor: «Hay que superar cierto prejuicio con respecto a la responsabilidad en el tea- tro para poder escuchar lo que Hugo Capriota dice. Y creerle si uno tiene ganas. Porque yo creo que tiene razón en casi todo» (Durán, 2003).

\section{Referencias}

Damore, D. (2009, 4 de abril). "Peripecias en el país del desastre". Clarín. Buenos Aires, Argentina. Recuperado de http://edant.revistaenie.clarin.com/notas/2009/04/04/_-01889917.htm

Di Pietro, L. (2009). Le théâtre d'Eduardo Pavlovsky. (Tesis de maestría). Université Sorbonne Nouvelle-Paris 3, París, Francia.

Di Pietro, L. (2014). Théâtre argentin 1983-2003: Une esthétique de la décomposition. (Tesis doctoral). Universidad de Perpignan, Perpiñán, Francia.

Dosio, C. (2008). El Caraja-jí. Buenos Aires: Libros del Rojas.

Duran, A. (2003). La crisis argentina a través de una telenovela papanatas. Revista Picadero, (10).

Grotowsky, J. (1968). Hacia un teatro pobre. Madrid: Siglo XXI Editores.

Martin, J., \& Perrier, J. L. (2010). Buenos Aires, génération théâtre indépendant. París: Les solitaires intempestifs.

Ordoñez, M. (2009, 29 de noviembre). A sus plantas rendido un león. Babelia (suplemento de El País). Madrid, España.

Rodríguez, M. (2008). El teatro de la desintegración. En O. Pelletieri (coord.), Historia del teatro argentino en Buenos Aires 1976-1998. Buenos Aires: Galerna.

Topuzian, M. (2004). Política y representación: Bizarra, una saga argentina, de Rafael Spregelburd. Actas del Congreso Internacional de Literatura, Mar del Plata, UNMDP.

Spregelburd, R. (2004). La estupidez, El pánico. Buenos Aires: Atuel.

Spregelburd, R. (2008a). Bizarra. Buenos Aires: Editorial Entropía.

Spregelburd, R. (2008b). Todo es relativo. Pero esto depende. Otra Parte, (15). Buenos Aires: primavera 2008. 